\title{
BURSA-ACEMLER BÖLGESİ DES VE DP VERİLERİ İLE ISIL UÇLAŞMA MODELLEMESİ
}

\author{
Petek SINDIRGI*
}

Dokuz Eylül Üniversitesi, Mühendislik Fakültesi, Jeofizik Mühendisliği Bölümü, İzmir, Türkiye

\begin{tabular}{ll}
\hline Anahtar Kelimeler & Öz \\
\hline Doğal Potansiyel, & Doğada, basınç, sıcaklık ve derişim farklılı̆ı nedeniyle uçlaşma akımları meydana gelir. \\
Sıcaklık, & Doğal potansiyel (DP) yöntemi, yorumlama çalışmalarında geleneksel olarak \\
Uçlaşma. & kullanılagelen popüler jeofizik araç olup, bu yöntem uçlaşma akımlarının yarattığı doğal \\
& potansiyel farklarının ölçülmesine dayanır. Bu çalışmada, ısıl uçlaşma problemi \\
& kümelenmiş elemanlar ağı modeli ile çözülerek bir jeotermal alana uygulanmıştır. Bu \\
& yöntemin diğer geleneksel jeofizik yöntemlere klyasla temel üstünlügü, incelenen \\
& sistemin karmaşı doğası hakkında daha detaylı bilgi verebilmesidir. Bursa ili Çekirge \\
& Mahallesi'nin kuzeybatısında yer alan Acemler Mevkiinden toplanan düşey elektrik \\
& sondaj (DES) ve DP verileri öncelikle geleneksel yöntemlerle(ters çözüm) \\
& değerlendirilmiş, elde edilen parametreler kullanılarak alanın ısıl uçlaşma modeli \\
& kurulmuştur. Böylece jeotermal alan için en uygun termal ve jeofizik parametre değerleri, \\
& kaynak yerleri ve sayları ile jeolojik birimlerin geometrik yapıları saptanmıştır. Bu \\
& çalışma ile elde edilen sonuçlar, ısıl uçlaşma yönteminin DP verilerinin yorumlanmasında \\
& güçlü bir araç oluşturduğunu ve jeotermal sistemlerin çeşitli özelliklerinin \\
& belirlenmesinde etkin şekilde kullanılabileceğini göstermiştir.
\end{tabular}

\section{THERMAL COUPLING MODELLING WITH THE VES AND SP DATA OF BURSA-ACEMLER} REGION

\begin{tabular}{ll}
\hline Keywords & Abstract \\
\hline $\begin{array}{l}\text { Self Potential, } \\
\text { Temperature, }\end{array}$ & In nature, due to differences in pressure, temperature and concentration, coupling flows occur. \\
Coupling. & The self potential (SP) method is the popular geophysical instrument traditionally used \\
in interpretation studies, which is based on the measurement of the natural potential \\
differences created by the coupling flows. In this study, the thermal coupling problem was \\
solved by a lumped elements network model and applied to a geothermal field. The basic \\
advantage of this method over the other traditional geophysical methods that it can \\
provide more detailed information about the complex nature of the system under \\
consideration. The vertical electric sounding (VES) and SP data collected from the \\
Acemler Location in west of the Çekirge District of Bursa province were firstly evaluated \\
by traditional methods (inverse solution), and the thermal coupling model was \\
established by using the obtained parameters. Thus, the most appropriate thermal and \\
geophysical parameter values for geothermal fields, the location of the sources and their \\
numbers and the geometrical structures of the geological formations were determined. \\
The results obtained from this study showed that the thermal coupling method is a \\
powerful tool in the interpretation of SP data and it can be used effectively to determine \\
the various properties of geothermal systems.
\end{tabular}

Alıntı / Cite

Sındırgı, P., (2019). Bursa-Acemler Bölgesi DES ve DP Verileri ile Isıl Uçlaşma Modellemesi, Mühendislik Bilimleri ve Tasarım Dergisi, 7(4), 751-760.

\begin{tabular}{l|l|l}
\hline Yazar Kimliği / Author ID (ORCID Number) & \multicolumn{3}{|l}{ Makale Süreci / Article Process } \\
\hline P. Sindırgl, 0000-0002-1328-9988 & Başvuru Tarihi / Submission Date & 10.12 .2018 \\
& Revizyon Tarihi / Revision Date & 22.04 .2019 \\
& Kabul Tarihi / Accepted Date & 21.05 .2019 \\
& Yayım Tarihi / Published Date & 19.12 .2019 \\
\hline
\end{tabular}

\footnotetext{
* ilgili yazar / Corresponding author: petek.sindirgi@deu.edu.tr, +90-232-301-7270
} 


\section{Giriş}

Elektrokimyasal, elektrokinetik ve termoelektrik kaynakların ürettiği potansiyel farklılı̆̆ının ölçümüne dayanan doğal potansiyel yönteminde doğal gerilim belirtileri genel olarak, yerkabuğundaki basınç, sıcaklık, iyon ve akışkan hareketlerinden türer. Yer altındaki akışkan akımı, konveksiyon akımlarında artışa neden olurken, bu akımların elektriksel yapı ile etkileşimi de elektrik potansiyelini arttırır. Ayrıca, ortamların özdirenç farklılığı, sıcaklık, gözeneklilik gibi özellikleri de doğal gerilim belirtilerinin olușumundaki ana etkilerdir (Corwin ve Hoover, 1979).

Geleneksel doğal potansiyel modelleme yöntemleri, uçlaşmış küre (de Witte, 1948; Yungul, 1950) veya çubuk dipol (Meiser, 1962; Paul, 1965) gibi akım kaynakları esasına dayanır. Ancak bu yöntemler ana kaynağın doğasına yönelik çok az bilgi verebilmektedirler. Bu nedenle, özellikle sıvı akımı olan ve ısıl özellik gösteren bölgeler için, kaynağın bu tür özelliklerini de içeren çözümler yapılmaya çalıșılmıştır (Marshall v e Madden, 1959; Nourbehecht, 1963; Sill ve Johng, 1979). Bu çalışmalarda kaynak mekanizması ayrıntılı bir biçimde tartışılmış, sıcaklık ve basınç gibi birincil potansiyeller ile doğal potansiyel çözümlerini birleştiren teknikler geliştirmiştir. Bu yöntemde, genel uçlaşmış akım eşitliğinden (Onsager, 1931; Marshall ve Madden, 1959; Nourbehect, 1963) yararlanarak, önce birincil potansiyel problemi çözülmüş, daha sonra bu potansiyeller uçlaşma katsayıları dağılımı ile birleştirilerek elektrik kaynak terimleri hesaplanmıştır. Sayısal yöntemler yardımıyla da elektrik potansiyel dağılımı hesaplanmıștır. Yöntem, baraj sızdırması (Wilt ve Butler, 1990) ve jeotermal alan modellemelerinde (C o rwi n, 1990 ; Schima vd., 1996; Drahor ve Berge, 2006 ) uygulanmıştır. Yasukawa (1993) ise bu yöntemi, Bodvarsson (1982)'un akışkan ve ısı akımı modellemesi yapan PT adlı programı ile birleştirerek yeni bir bilgisayar programı haline getirmiş ve çeşitli alanlara uygulamıștır (Yasukawa vd., 2003; Yasukawa vd, 2005). Konu ile ilgili deneysel çalışmalar da bulunmaktadır (Ishido vd., 1983; Sheffer, 2007; Giampaolo vd., 2016).

Yöntem, yukarıda açıklanan literatürde uçlaşmış akım kaynaklarına dayalı bir yöntem olarak tanımlanarak tam bir isim verilmemiștir. Türkçe literatürde ise konu ile ilgili tek bir çalışma vardır ve bu çalışmada Sındırgı (2005); jeotermal alanlar için birincil akım ısı olarak kabul edildiği için yöntemi ısıl uçlaşma yöntemi olarak nitelemiştir.

Bu çalışmada, düşey elektrik sondaj (DES) verileri ve DP yönteminin yı̆̆ınsal veri kümeleri geleneksel ters çözüm teknikleri ile değerlendirilerek elde edilen tabaka özdirenç ve kalınlıkları ile uçlaşma açısı gibi parametrelerle, jeotermal ortamı karakterize edecek bazı ısıl parametreler birlikte dikkate alınarak jeolojik ortamın isıl uçlaşma modeli ortaya konmaya çalışılmıştır.

Çalışma içeriğinde, ısıl uçlaşma yönteminin kuramsal gelişimi ve iki örnek teorik model verildikten sonra, Bursa ilindeki bir jeotermal alandan toplanan DES ve DP verileri ile gerçek bir alan problemine uygulaması sunulacaktır.

Uygulanan Tam Schlumberger düşey elektrik sondaj (DES) yönteminde, görünür özdirenç değerleri $\left(\rho_{a}\right)$ bir log-log grafiğindeki yarı akım elektrot aralığına (AB / 2) göre çizdirilir. İki ve üç tabakalı durumlar için, tabakaların özdirenç değişimlerine bağlı olarak eğriler, K, H, Q ve A tipi olarak sinıflandırılır (Başokur, 2004). Daha sonra, sondaj eğrileri, yeraltı katmanlarının gerçek dirençlerini ve kalınlıklarını belirlemek üzere çeşitli tekniklerle (abak çakıştırma, ters çözüm gibi) yorumlanır.

Çalışmanın uygulama alanı olarak seçilen Bursa ilinde, jeoloji (Erişen ve Öngür, 1976), hidrojeoloji ve termal sulara ait jeokimyasal analiz çalışmaları yapılmıștır (Özgüler ve Ünay, 1978; Haklıdır, 2013). Bu çalışmalarda bölgeye, alüvyon, mermer, kireçtaşı, kumtaşı ve traverten birimlerinin hâkim olduğu ve düşük basınç ve sıcaklığa sahip akiferlerin neojen kumtaşı, kireçtaşı, marn ve alüvyon birimler içinde yer alabileceği saptanmıștır. Özgüler ve Ünay (1978), ısıtıcı kaynağın derin kaynaklı olduğunu, ayrıca kırık ve çatlakların akifer rolü oynadığını belirtmiştir. Son yıllarda ise, bölgenin sismik aktivitesinin(Gök ve Polat, 2012) ve yeraltısuyu kimyasının incelendiği (Haklıdır, 2013) çalışmalar mevcuttur.

\section{Materyal ve Yöntem}

Bir ortamda zorlayıcı bir kuvvet veya potansiyel farklılığına yol açan sıvı, ısı, elektrik ve kütle akımlarına genel olarak uçlaşma nedeniyle oluşan akımlar denir. Uçlaşma nedeniyle oluşan akımlar matris formunda,

$$
\left|\begin{array}{l}
\vec{J}_{f} \\
\vec{J}_{h} \\
\vec{J}_{e} \\
\vec{J}_{m}
\end{array}\right|=\left|\begin{array}{llll}
L_{11} & L_{12} & L_{13} & L_{14} \\
L_{21} & L_{22} & L_{23} & L_{24} \\
L_{31} & L_{32} & L_{33} & L_{34} \\
L_{41} & L_{42} & L_{43} & L_{44}
\end{array}\right| \cdot\left|\begin{array}{c}
\vec{\nabla} P \\
\vec{\nabla} T \\
\vec{\nabla} V \\
\vec{\nabla} C
\end{array}\right|
$$

yazılabilir. Burada, $\vec{J}_{f} ; \vec{\nabla} P$ basınç gradyentine bağlı akışkan akımı, $\dot{J}_{h} ; \vec{\nabla} T$ sıcaklık gradyentine bağlı ısı akımı, $\vec{J}_{e} ; \quad \vec{\nabla} V$ elektrik potansiyeli gradyentine bağlı elektrik akımı ve $\vec{J}_{m}$ ise $\vec{\nabla} C$ derişim gradyentine bağlı oluşan iyonik akımı göstermektedir. Genel olarak, 
kararlı hal için akım eşitliği (Onsager,1931; Marshall ve Madden, 1959; Nourbeheceht, 1963; Sill, 1983);

$$
\vec{J}_{i}=\sum_{j} L_{i j} \vec{X}_{j}
$$

olarak verilir. Bazı diğer birincil akımlardan oluşan ikincil akımların birincil akımların üzerine etkisi küçüktür. Bu durumda birincil ve ikincil akımlar genel olarak aşağıdaki gibi verilir:

$$
\begin{aligned}
& \vec{J}_{1}=L_{11}-\vec{\nabla} \zeta \\
& \vec{J}_{T o p}=\vec{J}_{2}=-L_{21} \vec{\nabla} \zeta-\sigma \vec{\nabla} V
\end{aligned}
$$

Burada, $\vec{J}_{1}$; birincil akımı (ısı, çözelti, elektrik vb.), L11;

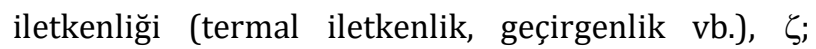
birincil potansiyeli (sıcaklık, basınç vb.), $\vec{J}_{\text {Top }}$; toplam elektrik akımını, $\vec{J}_{2}$; ikincil akımı, L21; uçlaşma iletkenliği, $\sigma$; elektriksel iletkenliği ve $\mathrm{V}$ ise elektrik potansiyelini göstermektedir. Eșitlik 4'ün sağ tarafının ilk kısmı, birincil akım nedeniyle olușan dolașım (konveksiyon) akımı, ikinci kısmı ise elektrik potansiyeli gradyenti nedeniyle oluşan iletim (kondüksiyon) akımıdır. Bu durumda Eşitlik 4;

$$
\vec{J}_{\text {Top }}=\vec{J}_{k o n v}+\vec{J}_{k o n d}
$$

şeklinde yazılabilir. Doğal potansiyel ölçümlerinde dıș akım kaynağı bulunmadığı için doğru akım koşulları geçerlidir ve toplam akım diverjansı sıfırdır $\left(\vec{\nabla} \cdot \vec{J}_{\text {Top }}=0\right)$. Bu durumda;

$$
\begin{aligned}
& \vec{\nabla} \cdot \vec{J}_{\text {kond }}=-\vec{\nabla} \cdot \vec{J}_{\text {konv }}=\vec{\nabla}\left(L_{21} \vec{\nabla} \xi\right) \\
& \text { ve } \\
& \quad \vec{\nabla} \cdot\left(L_{21} \vec{\nabla} \zeta\right)=\vec{\nabla} L_{21} \cdot \vec{\nabla} \zeta+L_{21} \vec{\nabla}^{2} \zeta=-\vec{\nabla} \cdot(\sigma \vec{\nabla} V)
\end{aligned}
$$

olur. Burada Eşitlik 7'nin sol tarafı sıcaklık ya da basınç nedeniyle olan değişimi ifade eder. Sağ tarafı ise bilinen doğru akım iletim denklemidir. $\mathrm{Bu}$ eşitliklerden yararlanarak, ısı akısı, geçirgenlik veya ısıl iletkenlik katsayıları, isıl elektrik potansiyeli katsayıları ve elektriksel özdirenç dağılımı bilinen ortamların iki boyutlu sıcaklık veya basınç dağılımları; ayrıca doğal potansiyelleri elde edilebilir.

"S" kaynağı sembolize etmek üzere, birincil akım ile kaynağın ilişkisi;

$$
\vec{\nabla} \cdot \vec{J}_{1}=S
$$

şeklinde verilir (Madden,1971). Verilen eşitlikler sayısal olarak çözülürken, Eşitlik 3'teki L11 iletkenliğinin y-yönünden bağımsız olduğu, ortamın y-yönünde, $[-\infty, \infty]$ aralığında, tekdüze ve izotrop olduğu varsayılır. $\vec{J}_{1}$ birincil akımı ve bunu doğuran $\zeta$ birincil potansiyelleri ise üç boyutludur ve y-yönünde tekdüze, izotrop bir ortamda çift fonksiyon özelliği gösterirler. $y$-yönündeki etkileri sabit hale getirmek amacıyla, Eșitlik 3 ve Eşitlik 8'in y-yönündeki Fourier kosinüs dönüşümleri alınarak dalgasayısı $(\lambda)$ ortamında çözüm yapılır. Buna göre, Eşitlik 3'ün yyönünde Fourier kosinüs dönüşümü alınarak;

$$
\begin{aligned}
& J_{x}(x, \lambda, z)=-L_{11} \frac{\partial \zeta(x, \lambda, z)}{\partial x} \\
& J_{z}(x, \lambda, z)=-L_{11} \frac{\partial \zeta(x, \lambda, z)}{\partial z}
\end{aligned}
$$

ve

$S(x, \lambda, z)=\frac{\partial J_{x}}{\partial x}+\frac{\partial J_{z}}{\partial z}+\lambda^{2} L_{11} \zeta$

elde edilir. $\mathrm{Bu}$ eşitlikler yer altı modelinin her bir noktası için kümelenmiş elemanlar ağı (Lumpedelement rectangular network) oluşturularak çözülebilir(Sill, 1983; Yasukawa, 2003; Oliveti ve Cardarelli, 2017.) Bunun için;

$Y_{x}=L_{11} \Delta z / \Delta x$

$Y_{Z}=L_{11} \Delta x / \Delta z$

$Y=\lambda^{2} \Delta x \Delta z$

tanımlamaları kulla n ılarak (n, m) boyutlu bir ağda herhangi bir ( $i, j$ ) noktası için fark eşitliği; i=1, $2,3, \ldots . ., n$ iken,

$$
\begin{aligned}
& S(i, j) \Delta x \Delta z=Y_{x}(i, j-1)[\zeta(i, j-1)-\zeta(i, j)] \\
& +Y x(i, j)[\zeta(i, j+1)-\zeta(i, j)]+Y z(i-1, j) \\
& {[\zeta(i-1, j)-\zeta(i, j)]+Y z(i, j)[\zeta(i+1, j)} \\
& -\zeta(i, j)]+Y(i, j) \zeta(i, j)
\end{aligned}
$$

şeklinde yazılabilir (Şekil 1)(Sill, 1983). Eşitlik 15 genel olarak tüm ağ için matris formunda;

$$
\vec{C} \zeta=\vec{S}
$$

olarakgösterilir. M a t r i s çözümünden elde edilen $\zeta(\lambda)$ dalgasayısı değerleri, üç boyutlu uzay ortamına, y-yönünde Ters Fourier Dönüșümü alınarak geçirilir. Artık potansiyel değerleri (sıcaklık veya basınç) hesaplandığından, Eşitlik 7'de yerine yazılabilir. $\mathrm{Bu}$ denklemden elektriksel kaynak terimleri her nokta için hesaplanır. Aynı eşitliğin sağ tarafındaki $(\sigma=1 / \rho)$ terimi bilindiğinden, elektrik potansiyeller de bulunabilir. 


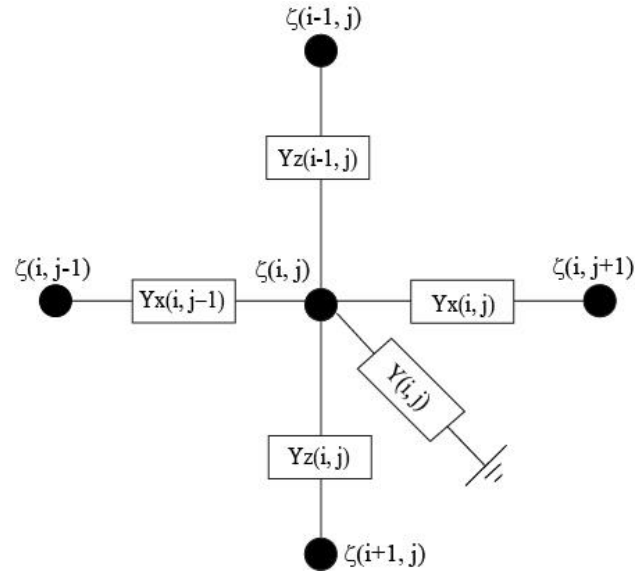

Şekil 1. Kaynak fonksiyonunun sayısal çözümü için oluşturulan kümelenmiş elemanlar ağı (Sill, 1983)

Jeotermal alanlardaki doğal gerilim belirtilerinin sıcaklık ya da basınca bağlı olarak oluştuğu bilinmektedir. Doğal gerilime neden olan birincil potansiyelin sıcaklık (T), bundan doğan birincil akımın ısı akımı $\left(\vec{J}_{h}\right)$, ikincil akımın ise elektrik akımı $\left(\vec{J}_{e}\right)$ olduğu düşünüldüğünde, uçlaşma bağıntıları,

$\vec{J}_{h}=-K \cdot \vec{\nabla} T$

$\vec{J}_{e}=-C \vec{\nabla} T-\sigma \vec{\nabla} V$

şeklini alır (Sill ve Johng, 1979). Burada; K; ortamın ısıl iletkenliği, C; ısıl elektrik potansiyel katsayısı olup, uçlaşma iletkenliğinin elektrik iletkenliğe oranıdır (C $=\mathrm{L}_{21} / \sigma$ ). Çeşitli kayaç birimleri için ısıl iletkenlik ve ısıl elektrik potansiyel katsayıları değişim aralıkları Tablo 1 'de verilmiștir.

Eşitlik 17, Fourier ısı iletim bağıntısıdır ve sıcaklık dağılımı bu eşitlikten elde edilebilir. Sıcaklık değerleri ile birlikte ısıl elektrik potansiyel katsayıları bir arada kullanılarak elektrik kaynak terimleri de bulunur. Elektrik kaynak terimleri bilindiğinde ise, sayısal yöntemlerle (sonlu farklar vb.) elektrik potansiyel hesaplanır. Özdirenç, ısıl iletkenlik ve ısıl elektrik potansiyel katsaylları gibi ortam parametreleri, oluşan elektrik potansiyeli etkilemektedir. Özellikle kaynağın gücü, ısıl iletkenlik ve ısıl elektrik potansiyel katsayıları doğal potansiyel belirtilerinin genlik ve biçimlerini önemli derecede etkilemektedir. Literatürde, değişik ortam parametreleri için pekçok kuramsal model üretilmiştir (Sill,1983; Sindırgl, 2005). Bu çalışmada ise, tekdüze homojen ortam ve dayk modelleri için çeşitli örnek modeller oluşturulmuştur. Arazi uygulamasında ise, Bursa ili Çekirge mahallesi kuzeybatısındaki Acemler mevkiinde toplanmış DES ve DP verileri kullanılarak sıcaklık uçlaşması modeli oluşturulmuştur.
Tablo 1. Çeşitli Jeolojik Yapılar için Fiziksel Parametrelerin Değer Aralıkları (Wilt,\&Butler, 1990)

\begin{tabular}{|c|c|c|c|c|}
\hline \multicolumn{2}{|c|}{ KAYAÇ TİPİ } & $\begin{array}{l}\text { Özdirenç } \\
\text { (ohm.m ) }\end{array}$ & $\begin{array}{c}\text { Isıl } \\
\text { İletkenlik } \\
\left(\mathrm{W} / \mathrm{m}^{\circ} \mathrm{C}\right)\end{array}$ & $\begin{array}{c}\text { Isıl } \\
\text { Elektrik } \\
\text { Potansiyel } \\
\text { Kats. } \\
\left(\mathrm{mV} /{ }^{\circ} \mathrm{C}\right)\end{array}$ \\
\hline \multirow{3}{*}{ 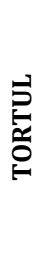 } & Kumtaşı & $5-100$ & $0.1-1.5$ & $0.04-0.1$ \\
\hline & Şeyl & $2-50$ & $0.2-2$ & $0.0 .5-0.5$ \\
\hline & Kireçtaşı & $20-500$ & $0.15-1.5$ & $0.0 .5-0.5$ \\
\hline \multirow{4}{*}{ 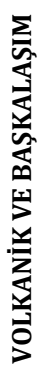 } & Granitik & $50-1000$ & $0.5-10$ & $0.1-2$ \\
\hline & Volkanik & $20-500$ & $1-15$ & $0.1-2$ \\
\hline & Başkalaş. & $50-1000$ & $0.5-10$ & $0.1-2$ \\
\hline & Kırıklı & $10-100$ & $0.05-0.5$ & $0.1-2$ \\
\hline
\end{tabular}

\subsection{Kuramsal Modeller}

Tekdüze homojen ortam ve dayk modelleri için oluşturulan kuramsal modellerde bazı parametreler sabit tutulurken diğer parametreler değiștirilmiș ve bu değişiminin DP anomalilerine etkileri incelenmiştir ( Tablo 2).

\subsubsection{Tekdüze homojen ortam modeli}

Tekdüze homojen ortam modelinde üç değișik durum incelenmiştir. Her üç durumda da noktasal sıcaklık kaynağı modelin tam ortasında yer almaktadır. Durumlardan ilkinde, sabit özdirenç $(\rho=200 \Omega \mathrm{m})$, ısıl elektrik potansiyel katsayıs $\left(\mathrm{C}=0.1 \mathrm{mV} /{ }^{\circ} \mathrm{C}\right)$ ve isıl iletkenliğe $\left(\mathrm{K}=15 \mathrm{~W} / \mathrm{m}^{\circ} \mathrm{C}\right)$ sahip tekdüze, homojen ortam için değişken kaynak güçleri incelenmiştir. $0.01 \mathrm{MW}$ ve $0.04 \mathrm{MW}$ güçlerindeki kaynaklar için hesaplanan doğal gerilim değişimleri, ilgili model ve parametreleri Şekil 2.a'da verilmiştir.

İkinci durumda, gücü $0.1 \mathrm{MW}$, özdirenci $200 \Omega \mathrm{m}$ ve ısıl elektrik potansiyel katsayıs $\mathrm{C}=0.1 \mathrm{mV} /{ }^{\circ} \mathrm{C}$ olan ortamın, ısıl iletkenliği 1,5 ve $6 \mathrm{~W} / \mathrm{m}^{\circ} \mathrm{C}$ olarak değiştirilmiștir. $\mathrm{Bu}$ duruma ait model, parametreleri ve ısıl iletkenliklerin değişimine bağlı olarak hesaplanan doğal gerilim grafikleri Şekil 2.b'de verilmiştir. 
Tablo 2. Kuramsal modellerde kullanılan parametre değerleri

\begin{tabular}{|c|c|c|}
\hline Model & $\begin{array}{c}\text { Sabit } \\
\text { Parametreler }\end{array}$ & Değişken Parametreler \\
\hline \multirow{3}{*}{$\begin{array}{c}\text { Tekdüze } \\
\text { Hom. } \\
\text { Ortam }\end{array}$} & $\begin{array}{l}\text { I.DURUM: } \\
\rho=200 \Omega \mathrm{m} \\
\mathrm{C}=0.1 \mathrm{mV} /{ }^{\circ} \mathrm{C} \\
\mathrm{K}=15 \mathrm{~W} / \mathrm{m}^{\circ} \mathrm{C}\end{array}$ & $\begin{array}{l}\text { Kaynak gücü } \\
(S=0.01 \mathrm{MW} \text { ve } 0.04 \mathrm{MW})\end{array}$ \\
\hline & $\begin{array}{l}\text { II.DURUM: } \\
\mathrm{S}=0.1 \mathrm{MW} \\
\rho=200 \Omega \mathrm{m} \\
\mathrm{C}=0.1 \mathrm{mV} /{ }^{\circ} \mathrm{C}\end{array}$ & $\begin{array}{l}\text { Isıl iletkenlik } \\
\left(1,5 \text { ve } 6 \mathrm{~W} / \mathrm{m}^{\circ} \mathrm{C}\right)\end{array}$ \\
\hline & $\begin{array}{l}\text { III.DURUM: } \\
\mathrm{S}=0.1 \mathrm{MW} \\
\rho=200 \Omega \mathrm{m} \\
\mathrm{K}=15 \mathrm{~W} / \mathrm{m}^{\circ} \mathrm{C}\end{array}$ & $\begin{array}{l}\text { Isıl el. pot. kats. } \\
\left(0.1,2 \text { ve } 5 \mathrm{mV} /{ }^{\circ} \mathrm{C}\right)\end{array}$ \\
\hline \multirow{3}{*}{ Dayk } & $\begin{array}{l}\text { I.DURUM: } \\
\text { Her üç bölgede, } \\
\mathrm{K}=8 \mathrm{~W} / / \mathrm{m}^{\circ} \mathrm{C} \\
\text { ve } \\
\mathrm{C}=1 \mathrm{mV} /{ }^{\circ} \mathrm{C} \\
\text { aynı }\end{array}$ & $\begin{array}{l}\rho_{1}=\rho_{3}>\rho_{2} \\
\rho_{1}=\rho_{3}<\rho_{2}\end{array}$ \\
\hline & $\begin{array}{l}\text { II.DURUM: } \\
\text { Her üç bölge de, } \\
\rho=1 \Omega \mathrm{m} \text { ve } \\
\mathrm{C}=1 \mathrm{mV} /{ }^{\circ} \mathrm{C} \\
\text { aynı }\end{array}$ & $\begin{array}{l}\mathrm{K}_{1}=\mathrm{K}_{3}=8 \mathrm{~W} / \mathrm{m}^{\circ} \mathrm{C}, \mathrm{K}_{2}=0.5 \\
\mathrm{~W} / \mathrm{m}^{\circ} \mathrm{C} \\
\mathrm{K}_{1}=\mathrm{K}_{3}=0.5 \mathrm{~W} / \mathrm{m}^{\circ} \mathrm{C}, \mathrm{K}_{2}=8 \\
\mathrm{~W} / \mathrm{m}^{\circ} \mathrm{C}\end{array}$ \\
\hline & $\begin{array}{l}\text { III.DURUM: } \\
\text { Her üç bölgede, } \\
\rho=1 \Omega \mathrm{m} \text { ve } \\
\mathrm{K}=8 \mathrm{~W} / \mathrm{m}^{\circ} \mathrm{C} \\
\text { aynı }\end{array}$ & $\begin{array}{l}\mathrm{C}_{1}=\mathrm{C}_{3}=0.1 \mathrm{mV} /{ }^{\circ} \mathrm{C}, \mathrm{C}_{2}=1 \\
\mathrm{mV} /{ }^{\circ} \mathrm{C} \\
\mathrm{C}_{1}=\mathrm{C}_{3}=1 \mathrm{mV} /{ }^{\circ} \mathrm{C}, \mathrm{C}_{2}=0.1 \\
\mathrm{mV} /{ }^{\circ} \mathrm{C} \\
\mathrm{C}_{1}=0.1 \mathrm{mV} /{ }^{\circ} \mathrm{C}, \mathrm{C}_{2}=1 \mathrm{mV} /{ }^{\circ} \mathrm{C}, \\
\mathrm{C}_{3}=2 \mathrm{mV} /{ }^{\circ} \mathrm{C}\end{array}$ \\
\hline
\end{tabular}

Tekdüze homojen ortam modeli için oluşturulan son durumda, kaynak gücü ve özdirenci ikinci durumla aynı olan modelin ısıl iletkenliği $15 \mathrm{~W} / \mathrm{m}^{\circ} \mathrm{C}$ olarak seçilmiştir. Isıl elektrik potansiyel katsayısı ise $0.1,2$ ve $5 \mathrm{mV} /{ }^{\circ} \mathrm{C}$ olarak değiştirilmiştir. Oluşturulan model, parametreleri ve ısıl elektrik potansiyel katsayısının değişimine bağlı olarak hesaplanan doğal gerilim grafikleri Şekil 2.c'de verilmiştir.

\subsubsection{Dayk modeli}

Dayk modeli üç kısımdan oluşmuştur. Modelin solu 1, ortası 2 ve sağı 3 numaralı ortam olarak adlandırılmıștır. Gücü $0.4 \mathrm{MW}$ olan noktasal sıcaklık kaynağl, modelin tam ortasına yerleştirilmiştir. $\mathrm{Bu}$ modelde de üç farklı durum incelenmiştir. İlk durumda, her üç bölgenin isll iletkenliği $(\mathrm{K}=$ $8 \mathrm{~W} / / \mathrm{m}^{\circ} \mathrm{C}$ ) ve 1 sil elektrik potansiyel katsayısı ( $\mathrm{C}=1$ $\mathrm{mV} /{ }^{\circ} \mathrm{C}$ ) aynıdır. Özdirençleri ise, 1 ve 3 . Bölgelerin aynı olacak şekilde 2 . Bölgeden daha büyük ve küçük olması durumları incelenmiştir. Bu duruma ait model, parametreleri ve bunlara bağlı olarak hesaplanan doğal gerilim anomalisi Șekil 3.a'da verilmiștir.

İkinci durumda, daykı temsil eden 2 numaralı bölgenin ısıl iletkenliği değiştirilip diğer parametreler sabit tutulmuştur. Tüm ortamların özdirenci $1 \Omega \mathrm{m}$, Isıl elektrik potansiyel katsayısı $1 \mathrm{mV} /{ }^{\circ} \mathrm{C}$ 'dir. Ikinci duruma ait model, parametreleri ve bunlara bağlı olarak hesaplanan doğal gerilim anomalisi Şekil 3.b'de verilmiștir.

Dayk modeli için son durumda ise, bu kez daykı temsil eden 2 numaralı bölgenin ısl elektrik potansiyel katsayısı değiştirilip diğer parametreler sabit tutulmuştur. Tüm ortamların özdirenci $1 \Omega \mathrm{m}$, ısıl iletkenliği $8 \mathrm{~W} / \mathrm{m}^{\circ} \mathrm{C}^{\prime}$ dir. Isıl elektrik potansiyel katsayısının her üç ortam için farklı olması hali de oluşturulmuştur. Üçüncü duruma ait model, parametreleri ve bunlara bağlı olarak hesaplanan doğal gerilim grafiği Şekil 3.c'de verilmiștir.

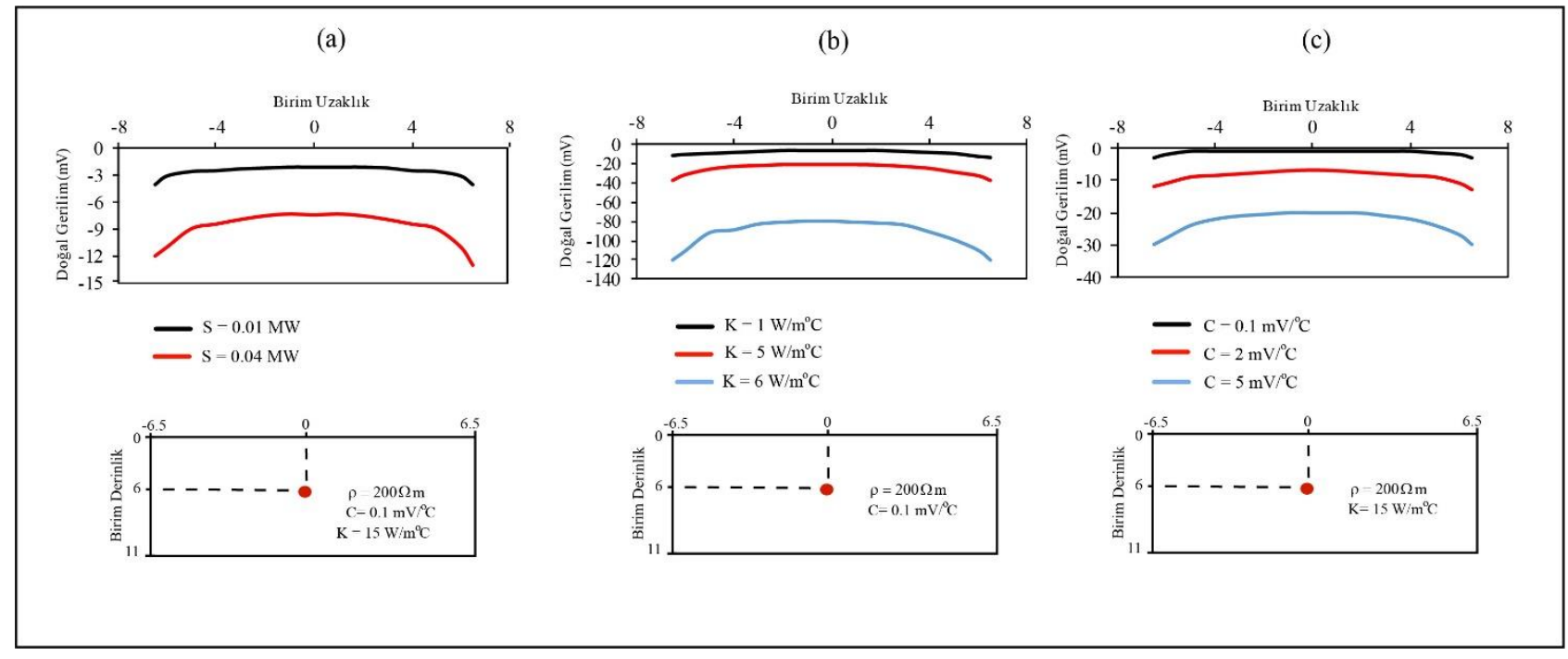

Şekil 2. Tekdüze homojen ortam modeli. (a) ısıl elektrik potansiyel katsayısı değişiminin DP'ye etkisi, (b)ısıl iletkenliğin değişiminin DP'ye etkisi,(c)kaynak güçlerinin değişiminin DP'ye etkisi 
(a)

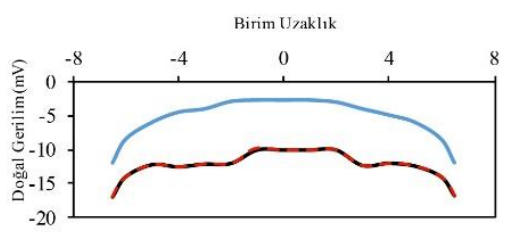

$-\rho_{1}=\rho_{2}=1 \Omega \mathrm{m}, \rho_{2}=100 \Omega \mathrm{m}$

$-\rho_{1}-\rho_{3}=1 \Omega \mathrm{m}, \rho_{2}-10 \Omega \mathrm{m}$

$-\rho_{1}=\rho_{3}=100 \Omega \mathrm{m}, \rho=1 \Omega \mathrm{m}$

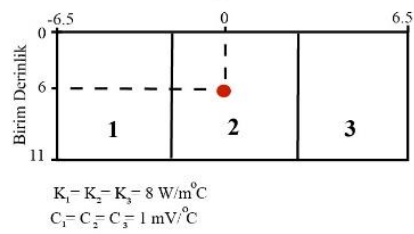

(b)

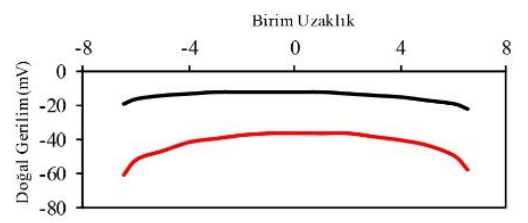

$-\mathrm{K}_{1}-\mathrm{K}_{3}-8 \mathrm{~W} / \mathrm{m}^{\circ} \mathrm{C}, \mathrm{K}_{2}-0.5 \mathrm{~W} / \mathrm{m}^{\circ} \mathrm{C}$
$\mathrm{K}_{1}-\mathrm{K}_{3}-0.5 \mathrm{~W} / \mathrm{m}^{\circ} \mathrm{C}, \mathrm{K}_{2}-8 \mathrm{~W} / \mathrm{m}^{\circ} \mathrm{C}$

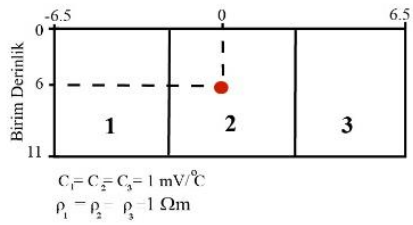

(c)
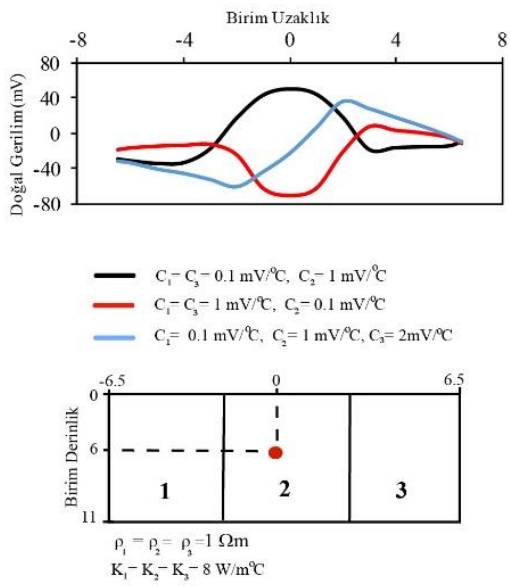

Şekil 3. Dayk modeli. (a)Özdirenç değişiminin DP’ye etkisi, (b)ısıl iletkenliğin değişiminin DP’ye etkisi,(c) ısıl elektrik potansiyel katsayısı değişiminin DP'ye etkisi

\section{Arazi Uygulamaları}

\subsection{Bursa ilinin jeolojisi ve hidrojeolojisi}

Bursa ovasını Uludağ masifinin çekirdeğini oluşturan granitler ve bunu kuşatan Uludağ metamorfik şistleri ve mermerleri, Karakaya formasyonu, Kalabakkaya formasyonu, neojen birimler, kuvaterner travertenlerler ve alüvyonlar oluşturur (Şekil 5). Bölgede genelde eğim atımlı normal faylar bulunmaktadır. Güneydoğudaki Demirkapı mahallesinden Kaynarca sıcak su kaynaklarına kadar uzanan bu faylar, birbirlerine parallel ve diyagonal kesecek şekilde uzanırlar. Güneyde Çekirge bölgesinde ve İnkaya Köyü civarında da bu tip faylar yer almaktadır. Bölgede ayrıca, Uludağ metamorfikleri Karakaya formasyonuna bindirme yapmaktadır (Erişen ve Öngür, 1976). Bölgedeki sıcak su kaynakları iki gruba ayrılabilir. Bunlardan Çekirge grubu sıcak su kaynakları, ortalama sıcaklıkları $28-50{ }^{\circ} \mathrm{C}$ arasında olan on adet kaynaktan olușur. Kaynarca grubu sıcak su kaynakları ise sıcaklıkları ortalama $35-82{ }^{\circ} \mathrm{C}$ arasında olan sekiz adet sıcak su kaynağından oluşur (Erișen vd., 1996).

\subsection{Bölgede Yapılan Özdirenç (DES) ve Doğal Potansiyel (DP) Uygulamaları}

Doğal potansiyel (DP) ve düsşey elektrik sondaj (DES) yöntemleri Bursa ili, Çekirge Mahallesinin yaklaşıı $1 \mathrm{~km}$ kuzeybatısında yer alan bir bölgede yapılmıștır. (Şekil 4 ve 5).

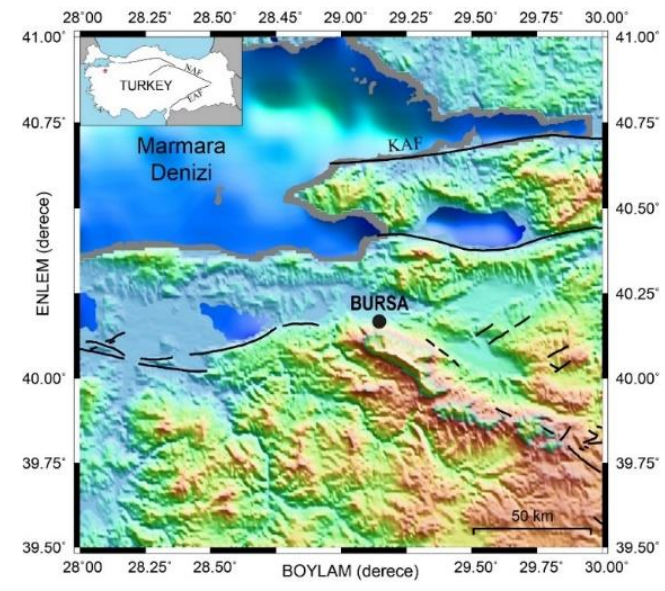

Şekil 4. Çalışma alanının yer bulduru haritası

Bölgede, açılım uzaklı̆ğ $240 \mathrm{~m}$. araştırma derinliğ i yaklaşık 60 m. olan, 40 m. aralıklı A1, A2, A3, A4 ve B1, B2, B3, B4 noktalarında Tam Schlumberger düșey elektrik sondaj (DES) ölçümleri yapılmıştır. Bu noktalardan oluşan A ve B profillerinin arasındaki uzaklık 80 metredir. Toplanan verilerinin, IPI2WIN v.2.1 (Bobachev vd., 2002) programı ile ters çözümleri yapılarak, DES noktaları altındaki elektrik tabakalanma modelini açlklayan ve her tabakaya ait olan derinlik ve gerçek özdirenç parametreleri hesaplanmıștır. Ters çözümleri yapılmıș DES noktalarına ait eğriler Șekil 6-7(a)'da, bu noktaların hesaplanmış özdirenç ve derinlikleri Tablo 3'te, oluşturulan görünür özdirenç kesitleri Şekil 6-7(b)'de, gerçek özdirenç kesitleri Şekil 6-7(c)'de, jeolojik yapı kesitleri ise Şekil 6-7(d)'de verilmiștir. 


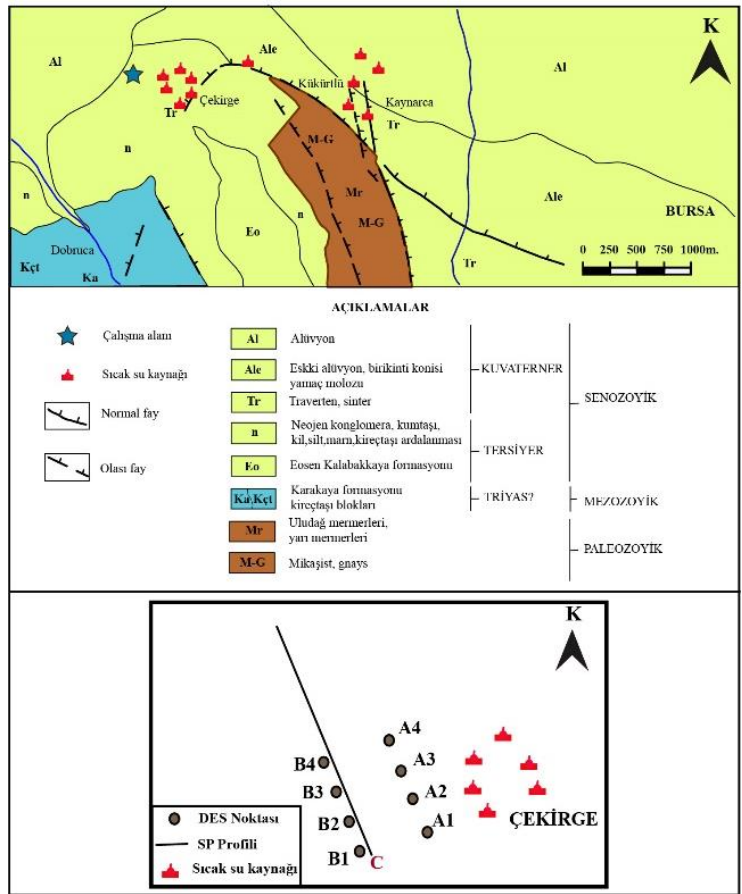

Şekil 5. Bursa bölgesine ait genel jeoloji haritası (Erişen vd., 1996'dan değiştirilmiştir) ve yapılan jeofizik çalışmalara ait gözlem noktaları

Kesitlerden ince bir yüzey örtüsü (0-5 m) altında, nispeten yüksek özdirençli ( 150-300 $\Omega \mathrm{m})$, yaklaşık 25 m. derinliğe kadar inen kil, kum ve çakıl içeren alüvyon birimlerin bulunduğu, bu birimin altında ise neojen yaşlı konglomera, kumtaşı, kil, silt, marn ve kireçtaşı ardalanmasının yer aldığı söylenebilir. Bu birimlerin oldukça düşük özdirence ( 5-20 $\Omega \mathrm{m})$ sahip olması nedeniyle sıcak su içerebileceği düşünülmüştür. Isıl uçlaşma modeli tasarlanırken, bu özellik göz önünde tutulmuștur

5 metre aralıklarla, 500 metre uzunluğundaki C profili boyunca toplanan doğal potansiyel ölçümlerinin yığınsal değerleri, uzaklığın fonksiyonu olarak grafiklenerek SPINV (Ram Babu ve Atchuta Rao, 1988) ters çözüm programı ile değerlendirilmiştir(Şekil 8(a)). Küre modeline göre değerlendirilen $\mathrm{C}$ profilinin uçlaşma açısı $20^{\circ}$ olarak hesaplanmıştır.
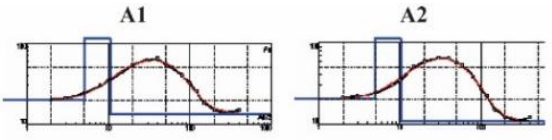

(a)
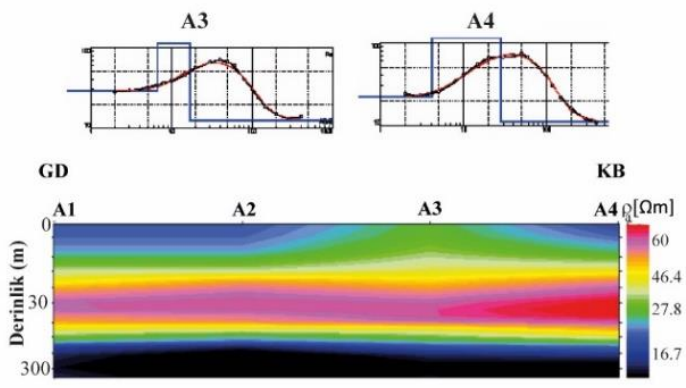

(c)

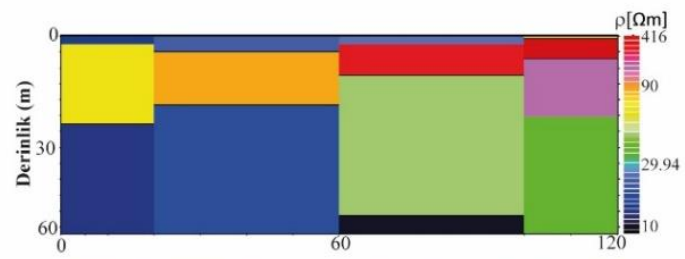

(d)

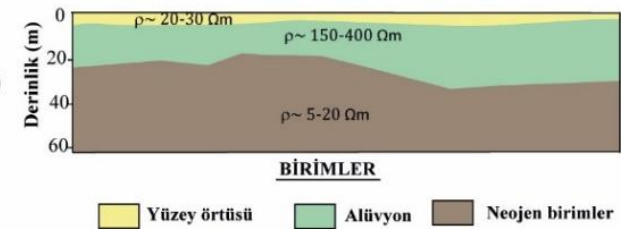

Şekil 6. DES yönteminin uygulandığı A profilinin Ters çözümü yapılmış (a)görünür özdirenç eğrileri, (b) görünür özdirenç yapma kesiti, (c) gerçek özdirenç kesiti ve (d) jeolojik yapı kesiti
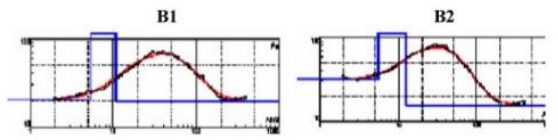

(a)
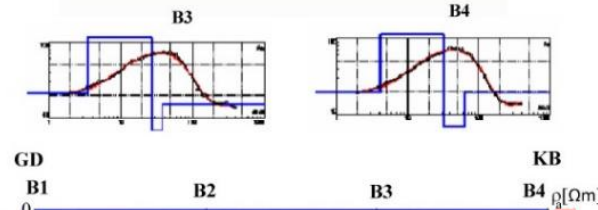

(b)

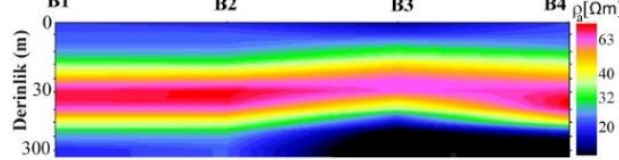

(c)

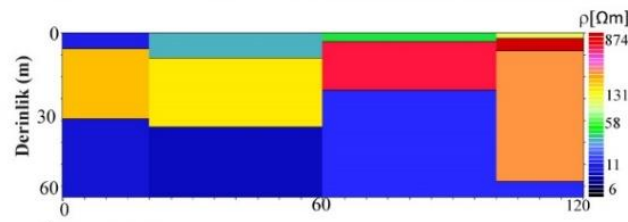

(d)

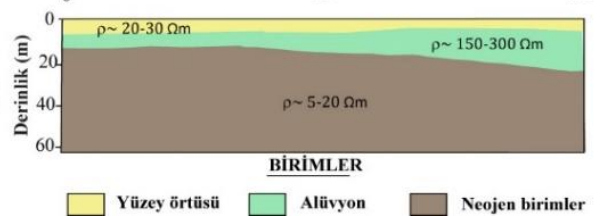

Şekil 7. DES yönteminin uygulandığı B profilinin Ters çözümü yapılmış (a)görünür özdirenç eğrileri, (b) görünür özdirenç yapma kesiti, (c) gerçek özdirenç kesiti ve (d) jeolojik yapı kesiti 
Tablo 3. A ve B profillerindeki DES noktalarının ters çözüm sonucu ulaşılan parametreleri

\begin{tabular}{|c|c|c|}
\hline Nokta No & Özdirenç $(\rho, \Omega m)$ & Tabaka kalınlığı (h, m) \\
\hline A1 & $\begin{array}{c}21 \\
201 \\
13\end{array}$ & $\begin{array}{c}5 \\
10\end{array}$ \\
\hline A2 & $\begin{array}{c}21 \\
397 \\
11 \\
\end{array}$ & $\begin{array}{c}5 \\
5.5\end{array}$ \\
\hline A3 & $\begin{array}{c}29 \\
146 \\
13\end{array}$ & $\begin{array}{l}6.6 \\
16\end{array}$ \\
\hline A4 & $\begin{array}{c}20 \\
184 \\
12 \\
\end{array}$ & $\begin{array}{c}4 \\
17\end{array}$ \\
\hline B1 & $\begin{array}{c}22 \\
407 \\
21 \\
\end{array}$ & $\begin{array}{l}6 \\
6\end{array}$ \\
\hline B2 & $\begin{array}{c}20 \\
402 \\
22 \\
\end{array}$ & $\begin{array}{c}5 \\
5.5\end{array}$ \\
\hline B3 & $\begin{array}{c}16 \\
157 \\
12 \\
\end{array}$ & $\begin{array}{c}2.5 \\
9\end{array}$ \\
\hline B4 & $\begin{array}{c}22 \\
167 \\
16\end{array}$ & $\begin{array}{c}5 \\
17\end{array}$ \\
\hline
\end{tabular}

\subsection{Isıl Uçlaşma Yöntemi Uygulamaları}

Elde edilen özdirenç ve doğal gerilim bilgileri birleștirilerek, Eşitlik 17 ve 18 ile verilen uçlaşmadan dolayı oluşan akımlar denklemlerinin düz çözümünden olası model ve parametrelerine ulaşmak amaçlanmıştır.

(a)

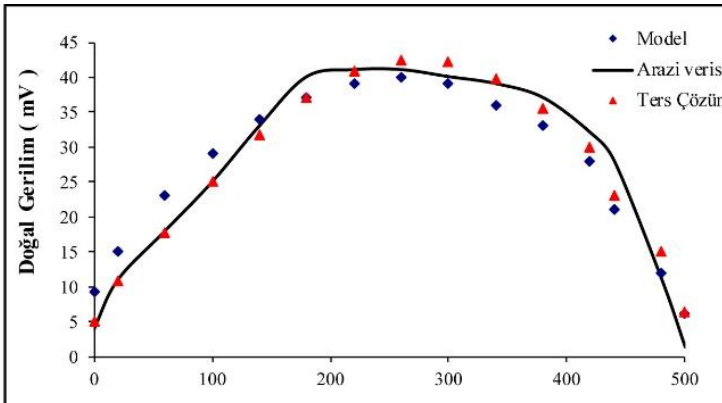

GD
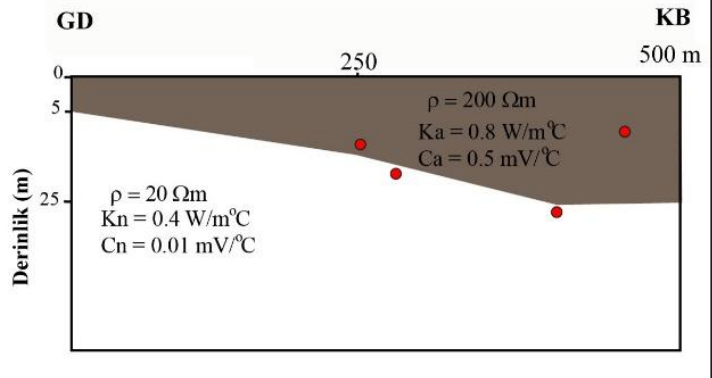

Şekil 8. (a) Bursa- Acemler bölgesinde C profilinde ölçülen, ters çözüm ve ısıl modele göre hesaplanan DP anomalileri, (b) isıl uçlaşma yöntemiyle oluşturulan model
Yöntem yeraltına uygulanırken, jeolojik yapı ile doğal potansiyel dağılımının hesaplanması için kullanılan ortam parametreleri (ortamın özdirenci, isıl iletkenliği, ısıl elektrik potansiyeli katsayıları) uyumlu olmalıdır. Bu nedenle oluşturulacak model için DES yönteminden elde edilen derinlik ve özdirenç bilgileri kullanılmıştır. Özdirenç değerleri, alüvyon için $200 \Omega$ $\mathrm{m}$, neojen birimler için ise $20 \Omega \mathrm{m}$. olarak seçilmiştir. Bölgede Isıl iletkenlik ölçümü verileri bulunmadığından Tablo 1'deki uygun kayaç tipine göre ısıl iletkenlik değeri ataması yapılmıștır. Ayrıca, modeldeki alüvyon ve neojen birimler arasındaki sınırın geometrisi, özdirenç yönteminden elde edilen kesitler ve DP yönteminin ters çözümünden elde edilen polarlanma açısı $\left(20^{\circ}\right)$ göz önünde tutularak belirlenmiştir. Özdirenç değerleri dışındaki model parametreleri, ortamdaki birimlere göre değiştirilerek en uygun model eğrisi elde edilene kadar sürdürülmüștür. Buna göre, neojen birimlerin ısıl iletkenliği $(\mathrm{Kn}) 0.4 \mathrm{~W} / \mathrm{m}{ }^{\circ} \mathrm{C}$, isl elektrik potansiyel katsayısı $(\mathrm{Cn}) 0.01 \mathrm{mV} /{ }^{\circ} \mathrm{C}$ ve alüvyonun ısıl iletkenliği (Ka) $0.8 \mathrm{~W} / \mathrm{m}^{\circ} \mathrm{C}$, ısıl elektrik potansiyel katsayısı (Ca) ise $0.5 \mathrm{mV} /{ }^{\circ} \mathrm{C}$ olarak seçilmiştir. Alüvyon ve onun altındaki neojen birimler arasındaki sınırlara yakın olarak dört adet termal kaynak modele yerleştirilmiştir (Şekil 8(b)). Modeldeki kaynakların güçleri 0.5 MW olarak alınmıştır. Ölçülen, ters çözümü yapılan ve bu modele göre hesaplanan doğal potansiyel değerleri Şekil 8(a)'da gösterilmiștir. Eğriler arasındaki uyumun oldukça iyi olduğu söylenebilir (Isıl uçlaşma modeli ve ters çözüm için Kök Ortalama Kare Hata(RMSE) sirasıyla; $3.77 \mathrm{mV}$ ve $2.42 \mathrm{mV}$ dur).

\section{Sonuç ve Tartışma}

Bu çalışmada, jeotermal bir alana ait ısıl ve jeofizik parametrelerinin birlikte kullanılmasıly sistemin modellenmesi hedeflenmiştir. Bu amaçla, kuramsal modeller üretilmiş ve gerçek bir alana yöntem uygulanmiştır.

Tekdüze, homojen ortam ve dayk kuramsal modelleri oluşturulurken, noktasal sıcaklık kaynaklarının yarattığı doğal gerilim belirtileri üzerinde ortamların özdirenç, ısıl iletkenlik, ısıl elektrik potansiyel katsayıları ve k a y a k gücünün değişiminin etkileri incelenmiștir. Tekdüze, homojen ortamda isıl iletkenliğin, ssıl elektrik potansiyel katsayılarının $\mathrm{v}$ e $\mathrm{k}$ a y $\mathrm{n} \mathrm{a} \mathrm{k}$ g ü c ü n ü n değișiminin doğal gerilim belirtilerinin şeklini az, genliğini ise önemli oranda etkilediği görülmüştür.

Dayk modelinde ise, daykın çevresiyle olan özdirenç ve ısıl iletkenlik farklılığının, belirtinin genliğini değiştirdiği görülmüştür. Hatta özdirenç değişiminin anomalide bir miktar şekil değişikliğine de yol açtığı söylenebilir. Dayk ve çevresinin isıl elektrik potansiyel katsayıları birbirinden farklı olduğu durumda, belirtilerin şekilleri birbirinden oldukça 
farklıdır. Doğal potansiyel belirtilerini en çok ısıl elektrik potansiyel katsayılarının etkilediği görülmüştür.

Alan çalışmasının yapıldığı Bursa Acemler bölgesinde doğal gerilim ve düşey elektrik sondaj yöntemleri uygulanmıştır. Isıl uçlaşma yöntemini uygulamak amacıyla, ölçülen özdirençlere ve bölgenin jeolojisine uygun bir model oluşturulmuştur. Model oluşturulurken, DP ve DES yöntemleri ile saptanan parametreler kullanılmıştır. Model parametreleri ve kaynak yerleri değiștirilerek ölçülen doğal potansiyel belirtilerine en uygun model eğrisi üretilmiștir. Buna göre, yüzeydeki alüvyon birimin; özdirencinin 200 $\Omega \mathrm{m}$., isıl elektrik potansiyel katsayısının $0.5 \mathrm{mV} /{ }^{\circ} \mathrm{C}$, ısıl iletkenliğinin $0.8 \mathrm{~W} / \mathrm{m}{ }^{\circ} \mathrm{C}$ ve altındaki neojen birimin, özdirencinin $20 \Omega \mathrm{m}$., isl elektrik potansiyel katsayısının $0.01 \mathrm{mV} /{ }^{\circ} \mathrm{C}$, ısıl iletkenliğinin $0.4 \mathrm{~W} / \mathrm{m}^{\circ} \mathrm{C}$ olabileceği belirlenmiştir. Elde edilen DES modellerinde kuzeybatıya doğru alüvyon kalınlığının arttığı gözlenmiştir. Ayrıca bu yönde Çekirge termal alanından da uzaklașılmaktadır. Isıl uçlașma modelinin geometrisine bu durum yansıtılmıștır. Modeldeki her iki birimin ısıl iletkenliklerinin çok büyük olmaması ve sıcaklık kaynağı sayısının az olması bu durumu açıklamaktadır.

Isıl uçlaşma yönteminde, ısıl iletkenliğin ölçülerek modellemede kullanılması uygundur. Ancak, çalışma alanına ait ölçülmüş ısıl iletkenlik verilerinin bulunmayıșı nedeniyle, bu parametreler deneme yanılma yöntemi ile modeldeki birimlere atanmıştır. $\mathrm{Bu}$ işlem yapılırken rasgele değil, Wilt ve Butler(1990)'ın belirlediği birimlere ait parametre aralıklarına uygun değerler verilmiştir.

$\mathrm{Bu}$ çalışma ile elde edilen sonuçlar, ısıl uçlaşma yönteminin, yukarıda bahsedilen bazı kabullerin yapılması şartıyla, DES ve DP verilerinin birlikte yorumlanmasında güçlü bir araç oluşturduğunu ve jeotermal sistemlerin çeşitli özelliklerinin belirlenmesinde etkin şekilde kullanılabileceğini göstermiştir.

\section{Teşekkür}

Bu çalışma, "Sıcak Alanlarda Jeofizik Modellemeler ve Uygulamaları, (2005)" adlı doktora tezinden üretilmiştir. Ayrıca Dokuz Eylül Üniversitesi Bilimsel Araştırmalar Koordinatörlüğü tarafından 02.KB.FEN.013 nolu bilimsel araștıma projesi kapsamında desteklenmiştir. Yazar Dokuz Eylül Üniversitesi Bilimsel Araştırmalar Koordinatörlüğü'ne teşekkür eder.

\section{Conflict of Interest / Çıkar Çatışması}

Yazar tarafından herhangi bir çıkar çatışması beyan edilmemiștir.

No conflict of interest was declared by the author.

\section{Kaynaklar}

Başokur, A. T., 2004. Düşey Elektrik Sondajı Verilerinin Yorumu. Ankara: A. Ü. , Müh. Fak. Jeofizik Müh. Bölümü.

Bobachev, A.A., Modin, I.N., Shevnin, V.A., 2002. IPI2WIN v2.1, Moscow State University, Geological Faculty, Department of Geophysics (yayınlanmamıștır).

Bodvarsson, G.S., 1982. Mathematical Modeling of the Behavior of Geothermal Systems under Exploitation, D o k t o r a Tezi. California Berkeley Üniversitesi, USA.

Corwin, R.F., 1990. The Self-Potential Method for Environmental and Engineering Applications. S.H. Ward (Edt.), Geotechnical and Environmental Geophysics içinde, (s. 127-145), Tulsa: Society of Exploration Geophysicists.

Corwin, R.F., Hoover, D.B.,1979. The Self-potential Method in geothermal exploration. Geophysics, $44,226-245$

de Witte, L., 1948. A New Method of I nterpretation of Self-Potential Data. Geophysics, 13, 600-608.

Drahor M.G., Berge M.A., 2006. Geophysical Investigations of the Seferihisar Geothermal Area, Western Anatolia, Turkey. Geothermics, 35, 302320 .

Erișen B., Öngür T., 1976. Bursa City Thermal Water Study. Report No: 5659. Mineral Research and Exploration Institute (MTA), Ankara, Turkey.

Erişen, B., Akkuş, İ., Uygur, N., Koçak, A., 1996. Türkiye Jeotermal Envanteri. Ankara: Maden Tetkik ve Arama Genel Müdürlüğü.

Giampaolo V., Calabrese, D., Rizzo, E., 2016. Transport Processes in Porous Media by Self-Potential Method. Applied and Environmental Soil Science, 2016, 1-12.

Gök, E., Polat, 0., 2012. An Assessment of the Seismicity of the Bursa Region from a Temporary Seismic Network. PAGEOPH, 169, 659-675.

Haklıdır, F.S.T., 2013. Hydro-geochemical Evaluation of Thermal, Mineral and Cold Waters between Bursa City and Mount Uludağ in the South Marmara Region of Turkey. Geothermics, 48, 132-145.

Ishido, T., Mizutani, H., Baba, K., 1983. Streaming Potential Observations, Using Geothermal Wells and In Situ Electrokinetic Coupling Coefficients under High Temperature. Tectonophysics, 91, 89104. 
Madden, T.R., 1971. The Resolving Power of Geoelectric Measurements for Delineating Resistive Zones with the Crust. T.G. Haecock (Edt.), The Structure and Physical Properties of the Earth's Crust. AGU Monograph Series-14 içinde (s.95). Washington DC: American Geophysical Union.

Marshall, D.J., Madden, T.R., 1959. Induced Polarization, a Study of Its Causes. Geophysics, 24, 790.

Meiser, P., 1962. A M ethod for Quantitative I nterpretation of Self-Potential Measurements. Geophys. Prospect., 10, 203-218.

Nourbehecht, $\quad$ B., $1963 . \quad$ Irreversible Thermodynamics Effects in Inhomogenous Media and their Application in Certain Geoelectric Problems. Doktora Tezi. M.I.T., USA.

Oliveti, I., Cardarelli E., 2017. 2D Approach for Modelling Self-Potential Anomalies: Application to Synthetic and Real Data. Bollettino di Geofisica Teorica ed Applicata, 58, 415-430.

Onsager, L., 1931. Reciprocal Relations in Irreversible Processes I. Physical Review, 37, 405-426.

Özgüler, M.E., Ünay, T., 1978. Bursa Ovası Jeotermal Enerji Aramaları Rezistivite Etüd Raporu, MTA Rapor No:6255, Ankara, Türkiye.

Paul, K., 1965. Direct interpretation of self potential anomalies caused by inclined sheet of infinite horizontal extension. Geophysics, 30, 418-423.

Ram Babu, H.V., Atchuta Rao, D., 1988. A Rapid Graphical Method for the Interpretation of the Self-Potential Anomaly over a Two-Dimensional Inclined Sheet of Finite Depth Extent. Geophysics, 53, 1126-1128.

Sheffer R. M., 2007. Forward Modelling and Inversion of Streaming Potential for the Interpretation of Hydraulic Conditions from Self-Potential Data. Doctorate thesis, The University of British Columbia, Canada.

Sindirgı P., 2005. Sicak Alanlarda Jeofizik Modellemeler ve Uygulamaları, Doktora Tezi, Dokuz Eylül Üniversitesi, Türkiye.

Sill, W.R., Johng, D.S., 1979. Self Potential Survey, Roosevelt Hot Spring, UTAH. DOE/DGE topical report. University of Utah.

Sill, W.R., 1983. Self-Potential Modeling from Primary Flows. Geophysics, 48, 76-86.
Schima, S., Wilt, M., Ross, H.U.S., 1996. Modeling S elf-potential D ata in the Abraham and MeadowHatton G eothermal S ystems. Department of Energy, research summaries.

Wilt, M., Butler, D., 1990. Numerical Modeling of SP anomalies: Documentation of Program SPPC and A pplication in Geothechnical Applications of the Self-potential Method. Techncal Report No:4. Department of the Army Waterworks Experiments Station, Corps of Engineers, Mississipi, USA.

Yasukawa, K., 1993. A Coupled Self Potential (SP), Fluid a nd Heat Flow Model for Subsurface F luid Flow Systems. Y üks e k L i s a n s T e z i . California Üniversitesi, USA

Yasukawa, K., Mogi, T., Widarto, D., Ehara, S., 2003. Numerical Modeling of a Hydrothermal System Around Waita Volcano, Kyushu, Japan, Based on Resistivity and Self-Potential Survey Results, Geothermics, 32(1), 21-46.

Yasukawa, K., Ishido, T., Suzuki, I., 2005. Geothermal Reservoir Monitoring by Continuous SelfPotential Measurements, Mori Geothermal Field, Japan. Geothermics, 34(5), 551-567.

Yungul, S.H. 1950. Interpretation of Spontaneous Polarization Anomalies Caused by Spheroidal Orebodies. Geophysics, 15, 237-246. 